\title{
A Novel Long Non-Coding RNA, SOX21- AS1, Indicates a Poor Prognosis and Promotes Lung Adenocarcinoma Proliferation
}

\author{
Xiyi Lu ${ }^{a} \quad$ Chenjun Huang ${ }^{b} \quad$ Xuezhi He ${ }^{c}$ Xinyin Liu ${ }^{a}$ Jianmei Jid Erbao Zhange \\ Wei Wang ${ }^{\text {Renhua Guo }}{ }^{a}$ \\ aDepartment of Oncology, First Affiliated Hospital of Nanjing Medical University, Nanjing, ${ }^{\mathrm{b} D e p a r t m e n t}$ \\ of thoracic surgery, First Affiliated Hospital of Nanjing Medical University, Nanjing, 'Department of \\ Biochemistry and Molecular Biology, Nanjing Medical University, Nanjing, 'Department of Oncology, \\ Nantong Tumor Hospital, Affiliated Tumor Hospital of Nantong University, Nantong, eDepartment \\ of Epidemiology and Biostatistics, Jiangsu Key Lab of Cancer Biomarkers, Prevention and Treatment, \\ Collaborative Innovation Center for Cancer Personalized Medicine, School of Public Health, Nanjing \\ Medical University, Nanjing, People's Republic of China
}

\section{Key Words}

Long non-coding RNA • SOX21-AS1 • Cell proliferation • p57 • Lung adenocarcinoma

\begin{abstract}
Background: In recent years, long non-coding RNAs (IncRNAs) have been shown to be a novel class of regulators of cancer biological processes. Although IncRNAs are dysregulated in numerous cancer types, limited data are available on the expression profiles and potential functions of IncRNAs in lung adenocarcinoma (LUAD). This study evaluated the expression and biological roles of IncRNA SOX21 antisense RNA 1 (SOX21-AS1) in LUAD. Methods: Quantitative reverse transcription PCR (qRT-PCR) was performed to detect the expression levels of SOX21-AS1 in 68 pairs of LUAD tissues and corresponding non-tumor tissues. The effect of SOX21-AS1 on proliferation was evaluated by MTT, colony formation, EdU assays, flow-cytometric analysis and in vivo tumor formation assays. Real-time PCR, western-blot and immunohistochemistry were used to evaluate the mRNA and protein expression of p57. Results: Higher expression levels of SOX21-AS1 positively correlated with tumor size and advanced tumor-node-metastasis (TNM) stage. Multivariate analyses indicated that SOX21AS1 expression could serve as an independent prognostic factor for overall survival of LUAD. Furthermore, knockdown of SOX21-AS1 significantly inhibited LUAD cell proliferation both in vitro and in vivo and induced cell cycle phase arrest and cell apoptosis. Importantly, through qRT-PCR and western blot analysis, we found that inhibition of SOX21-AS1 remarkably induced p57 expression. Conclusions: Collectively, our study demonstrates that SOX21-AS1 is involved in the development and progression of LUAD and that SOX21-AS1 may be a potential diagnostic factor as well as a target for new therapies for patients with LUAD.

X. Lu, C. Huang and X. He contributed equally to this work.

Renhua Guo, Wei Wang

and Erbao Zhang

\section{KARGER}

Dept Oncol, and Dept Thoracic Surgery; First Affiliated Hospital of Nanjing Medical University, Nanjing, 210029 (PR China); Dept Epidemiol and Biostatistics, Jiangsu Key Lab of Cancer Biomarkers, Prevention and Treatment, Collaborative Innovation Center for Cancer Personalized Medicine, School of Public Health, Nanjing Medical University, Nanjing, 211166 (PR China); E-Mail rhguonjmu@sina.com / wangwei-doctor@163.com / erbaozhang@njmu.edu.cn
\end{abstract}




\section{Introduction}

Despite the current advances in cancer surgery, chemotherapy and molecular targeting therapy techniques for lung cancer, it remains the predominant cause of cancer-related death worldwide [1, 2]. According to the National Center for Health Statistics (NCHS), lung cancer is expected to account for $27 \%$ of all male cancer deaths and $26 \%$ of all female cancer deaths in 2016 [1,3]. Non-small cell lung cancer (NSCLC) accounts for approximately 85\% of all lung cancer cases, and lung adenocarcinoma (LUAD) is its most common histological type [4]. Currently, the 5-year overall survival rate for NSCLC patients is still approximately $15 \%$ because patients are typically at advanced stages when diagnosed [5]. Therefore, a better understanding of the molecular mechanisms underlying LUAD development and progression could improve the early diagnosis, treatment and overall prognosis of this disease.

With the development and innovation of whole genome and transcriptome sequencing technologies in the past decade, we have realized that more than $90 \%$ of the total mammalian genome can be transcribed into non-coding RNAs [6-8]. Long noncoding RNAs (lncRNAs), which are longer than $200 \mathrm{nt}$ in length $[9,10]$, are a class of non-protein-coding RNA that have been demonstrated to play essential roles in cellular development and differentiation, in the modulation of apoptosis and in multiple biological processes [11-15]. More importantly, numerous studies have revealed that aberrant lncRNA expression is involved in a wide range of human diseases, particularly cancers [16-24]. Mounting evidence in recent years has demonstrated that IncRNAs, such as MALAT1 [25], LINC00473 [26], AGAP2-AS1 [27] play crucial roles in NSCLC development and progression. LncRNA MALAT1 is a regulator of gene expression that governs the hallmarks of lung cancer metastasis. LINC00473 is a potential biomarker for the detection of lung cancers with inactivated LKB1. In our previous study, we found that p53-regulated TUG1 is downregulated in NSCLC and acts in part through the control of HOXB7 [28]. Upregulated LUADT1 could regulate LUAD proliferation via suppression of p27 expression [29]. In this regard, identifying cancer-associated lncRNAs is essential for understanding the progression of LUAD and for establishing better treatment methods.

In this study, we identified a new lncRNA, SOX21 antisense RNA 1 (SOX21-AS1), which is located at chromosome 13q32.1 and is transcribed into a $2986 \mathrm{nt}$ transcript. SOX21-AS1 was remarkably overexpressed in LUAD tissues compared with corresponding non-tumor tissues. We then discovered that elevated expression of SOX21-AS1 was associated with poor patient prognosis. Knockdown of SOX21-AS1 was found to suppress the proliferation of LUAD cells both in vitro and in vivo. Furthermore, our results showed that SOX21-AS1 may act as an oncogene partly through the repression of p57 in lung cancer. Our results demonstrate that IncRNA SOX21-AS1 may represent a novel indicator of poor prognosis and is a potential biomarker for the diagnosis and treatment of LUAD.

\section{Materials and Methods}

\section{Patients and tissue samples}

A total of 68 primary NSCLC patients who had undergone surgeries at the First Affiliated Hospital of Nanjing Medical University (China) between 2012 and 2014 were enrolled in this study. None of these patients had received chemotherapy or radiotherapy prior to surgery. Histological classifications and tumor-node-metastasis (TNM) stages were determined according to the National Comprehensive Cancer Network (NCCN) criteria. This study was approved by the Research Ethics Committee of Nanjing Medical University (Nanjing, Jiangsu, People's Republic of China), and written informed consent was obtained from all participants. The clinical characteristics of the NSCLC patients are summarized in Table 1.

Cell cultures

Six human NSCLC adenocarcinoma cell lines (A549, SPC-A1, NCI-H1299, NCI-H1650, PC9, and H1975), three NSCLC squamous carcinomas cell lines (H1703, SK-MES-1 and H226), and a normal human bronchial 


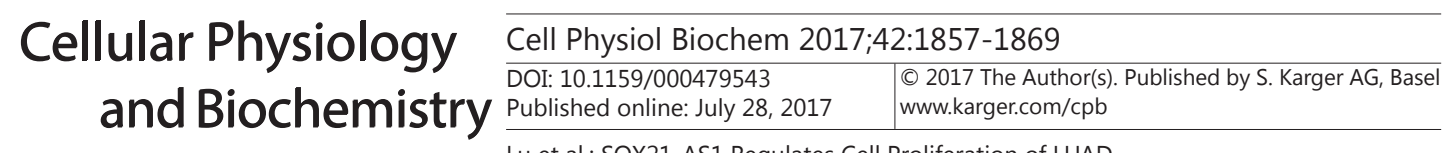

Lu et al.: SOX21-AS1 Regulates Cell Proliferation of LUAD

epithelial cell line (16HBE) were purchased from the Institute of Biochemistry and Cell Biology at the Chinese Academy of Sciences (Shanghai, China). The cells were cultured in RPMI 1640 or DMEM (GIBCO-BRL) supplemented with $10 \%$ fetal bovine serum (10\% FBS), $100 \mathrm{U} /$ $\mathrm{ml}$ penicillin, and $100 \mathrm{mg} / \mathrm{ml}$ streptomycin in incubators at $37^{\circ} \mathrm{C}$ with $5 \% \mathrm{CO}_{2}$.

\section{RNA extraction and $q R T-P C R$ analyses}

Total RNA was extracted from frozen tissues or cultured cells using the TRIzol reagent (Invitrogen, Grand Island, NY, USA) according to the manufacturer's instructions. For qRTPCR, the isolated RNA was reverse transcribed to cDNA using a PrimeScript RT reagent Kit (Takara, Dalian China). Real-time PCR analyses were performed with SYBR Green (Takara, Dalian China). The results were normalized to the expression of glyceraldehyde-3-phosphate dehydrogenase (GAPDH). The gene-specific primers were as follows: SOX21-AS1 forward, 5'-GGCTCAGGTTTAGGCGAGTG-3', and reverse, 5'-AGAGGCTCTCCTACTCGTGC-3'; GAPDH forward, 5'-AGCCACATCGCTCAGACAC-3', and reverse, 5'-GCCCAATACGACCAAATCC-3'; p15 forward, 5'-GGACTAGTGGAGAAGGTGCG-3', and reverse, 5'-GGGCGCTGCCCATCATCATG-3'; p16 forward,
Table1. The clinic-pathological factors of 68 NSCLC patients

\begin{tabular}{lll}
\hline Clinical factors & Number of cases & (\%) of patients \\
\hline Sex & 29 & \\
Male & 39 & 42.6 \\
Female & & 57.4 \\
Age & 36 & \\
S60 & 32 & 52.9 \\
$>60$ & & 47.1 \\
Histological grade & 13 & 19.1 \\
High & 19 & 27.9 \\
Middle & 12 & 17.6 \\
Middle to low & 23 & 33.8 \\
Low & 1 & 1.5 \\
Other & & \\
Histological classification & 39 & 57.4 \\
SCC (Squamous cell carcinoma) & 28 & 41.2 \\
AD (adenocarcinoma) & 1 & 1.5 \\
Other & & \\
Tumor stage & 21 & 30.9 \\
I & 27 & 39.7 \\
II & 18 & 26.5 \\
III & 2 & 2.9 \\
IV & & \\
Tumor (T) & 21 & 30.9 \\
T1 & 28 & 41.2 \\
T2 & 14 & 20.6 \\
T3 & 5 & 7.4 \\
T4 & & \\
Lymph node metastasis (N) & 30 & 44.1 \\
N0 & 31 & 45.6 \\
N1 & 6 & 8.8 \\
N2 & 1 & 1.5 \\
N3 & & \\
History of smoking & 36 & 52.9 \\
Ever & 32 & 47.1 \\
Never & & \\
\hline & &
\end{tabular}

5'-CACCGAATAGTTACGGTCGG-3', and reverse, 5'-GCACGGGTCGGGTGAGAGTG-3'; p21 forward, 5'-GTCCACTGGGCCGAAGAG-3', and reverse, 5'-TGCGTTCACAGGTGTTTCTG-3'; p27 forward, 5'-TGCAACCGACGATTCTTCTACTCAA-3', and reverse, 5'-CAAGCAGTGATGTATCTGATAAACAAGG-3'; and p57 forward, 5'-CTAGCCAGCAGGCATCGAG-3', and reverse, 5'-GTGGTGGACTCTTCTGCGTC-3' qRT-PCR and data collection were carried out on an ABI 7500 real-time PCR system (Applied Biosystems, Foster City, CA, USA). The relative expression of SOX21-AS1 was calculated and normalized using the $2^{-\Delta \Delta C t}$ method relative to GAPDH.

SiRNA and transfection of LUAD cells

Cells cultured on six-well plates were transfected with siRNA or non-specific control siRNA (si-NC) using Lipofectamine 2000 (Invitrogen, Shanghai, China) according to the manufacturer's protocol. Nonspecific siRNA (si-NC) was purchased from Invitrogen. Typically, cells were seeded on six-well plates and then transfected the next day with specific siRNA (100 nM) and control siRNA (100 nM) using Lipofectamine. Cells were harvested after $48 \mathrm{~h}$ for qRT-PCR and other experiments. The siRNA sequences were as follows: 5'AACAGAAACAGAGGCUUCUCGCAUU3' (sense) and 5'AAUGCGAGAAGCCUCUGUUUCUGUU3' (antisense) for siRNA 1\# and 5'CAGUUAACUUACAGUGUCUCACUUA3' (sense) and 5'UAAGUGAGACACUGUAAGUUAACUG3' (antisense) for siRNA 2\#.

Cell proliferation analyses and colony formation assays

Cell proliferation was measured using a Cell Proliferation Reagent Kit I (MTT) (Roche Applied Science). The A549 and NCI-H1299 cells were transfected with si-SOX21-AS1 or si-NC (3000 cells/well) and were plated in each well of 96-well plates. Cell viability was documented every $24 \mathrm{~h}$ according to the manufacturer's recommendations. For the cells to form colonies, a total of 700 si-SOX21-AS1 or si-NC A549 and NCI-H1299 cells were placed onto fresh six-well plates and maintained in media containing 10\% FBS, replacing the medium every $4 \mathrm{~d}$. After 2 weeks, the colonies were fixed with methanol and stained with $0.1 \%$ crystal violet (Sigma, St. Louis, MO). The visible colonies were manually counted. Each experiment was repeated at least three times independently. 


\section{Cellular Physiology Cell Physiol Biochem 2017;42:1857-1869 \\ \begin{tabular}{l|l} 
and Biochemistry Published online: July 28, 2017 & $\begin{array}{l}\text { (c) } 2017 \text { The Author(s). Published by S. Karger AG, Basel } \\
\text { www.karger.com/cpb }\end{array}$
\end{tabular}}

Lu et al.: SOX21-AS1 Regulates Cell Proliferation of LUAD

\section{Flow-cytometric analyses}

Transfected cells were harvested $48 \mathrm{~h}$ after transfection by trypsinization. Subsequent double staining with fluorescein isothiocyanate (FITC)-Annexin V and propidium iodide (PI) was performed using the FITC Annexin V Apoptosis Detection Kit (BD Biosciences) according to the manufacturer's instructions. The cells were analyzed using a flow cytometer (FACScan; BD Biosciences) equipped with Cell Quest software (BD Biosciences). The cells were categorized as viable cells, dead cells, early apoptotic cells, or apoptotic cells, and then the relative ratios of apoptotic cells were compared with control transfection from each experiment. For the cell-cycle analysis, the cells were stained with PI using the CycleTESTT PLUS DNA Reagent Kit (BD Biosciences) following the manufacturer's protocol and were then analyzed by FACScan. The percentages of cells in the G0-G1, S, and G2-M phases were counted and compared. All of the samples were assayed in triplicate.

\section{Ethynyldeoxyuridine (EdU) analysis}

A 5-ethynyl-2-deoxyuridine (EdU) labeling/detection kit (Ribobio, Guangzhou, China) was used to assess cell proliferation. The cells were cultured in 96-well plates at $5 \times 10^{3}$ cells/well. Forty-eight hours after transfection, $50 \mu \mathrm{M}$ EdU labeling media was added to the 96-well plates, and they were incubated for $2 \mathrm{~h}$ at $37^{\circ} \mathrm{C}$ under $5 \% \mathrm{CO}_{2}$. After treatment with $4 \%$ paraformaldehyde and $0.5 \%$ Triton X-100, the cells were stained with the anti-EdU working solution. DAPI was used to label the cell nuclei. The percentage of EdU-positive cells was calculated after fluorescence microscopy analysis. Five fields of view were randomly assessed for each treatment group.

Tumor formation in nude mice

Five-week-old male athymic BALB/c nude mice were maintained under specific pathogen-free conditions and were manipulated according to protocols approved by the Shanghai Medical Experimental Animal Care Commission. A549 cells were stably transfected with shSOX21-AS1 or empty vector using Lipofectamine 2000 (Invitrogen). After 48 h, the cells were collected and harvested at a concentration of $2 \times 10^{7}$ cells $/ \mathrm{ml}$. One hundred microliters of the cell suspension was subcutaneously injected into a single side of the posterior flank of each mouse. Tumor volumes and weights were examined every 2 days in mice from the control (four mice) or shSOX21-AS1 (four mice) groups; the tumor volumes were measured (length $\times$ width $^{2} \times 0.5$ ). Sixteen days after injection, the tumors were removed from all of the animals and, after the tumor weights were measured, were used for further analysis. The primary tumors were excised, and the tumor tissues were used to perform qRT-PCR analysis of SOX21-AS1 expression levels and immunostaining analysis of Ki-67 and p57 protein expression.

\section{Western blot assay and antibodies}

Cell protein lysates were separated by $10 \%$ sodium dodecyl sulfate-polyacrylamide gel electrophoresis (SDS-PAGE), transferred to 0.22- $\mu$ m nitrocellulose (NC) membranes (Sigma, USA), and incubated with specific antibodies. Autoradiograms were quantified by densitometry (Quantity One software; Bio-Rad). GAPDH antibody was used as control. Anti-p57 was purchased from Cell Signaling Technology (Boston, MA, USA).

\section{Statistical analysis}

All statistical analyses were performed using SPSS 22.0 software (IBM, SPSS, USA). The significance of differences between groups was estimated by Student's t-test and the $\chi 2$ test as appropriate. The overall survival (OS) rates were calculated using the Kaplan-Meier method with the log-rank test applied for comparison. Survival data were evaluated using univariate and multivariate Cox proportional hazards models. Variables with a value of $\mathrm{P}<0.05$ in univariate analyses were used in subsequent multivariate analyses on the basis of Cox regression analyses. Two-sided P values were calculated, and a probability level of 0.05 was considered to be statistically significant. 


\section{Results}

SOX21-AS1 expression is upregulated in human LUAD tissues and correlates with poor prognosis

We first analyzed RNA-Seq data (from TCGA: The Cancer Genome Atlas) for IncRNAs from lung adenocarcinoma tissues $(n=291)$ using the bioinformatics tool IncRNAtor (http://lncrnator.ewha.ac.kr/index.htm). The results revealed that S0X21-AS1 expression levels were upregulated approximately 5-fold in lung adenocarcinoma tissues (Fig. 1A). Then, we analyzed the expression of SOX21-AS1 in 40 LUAD tissue samples and adjacent

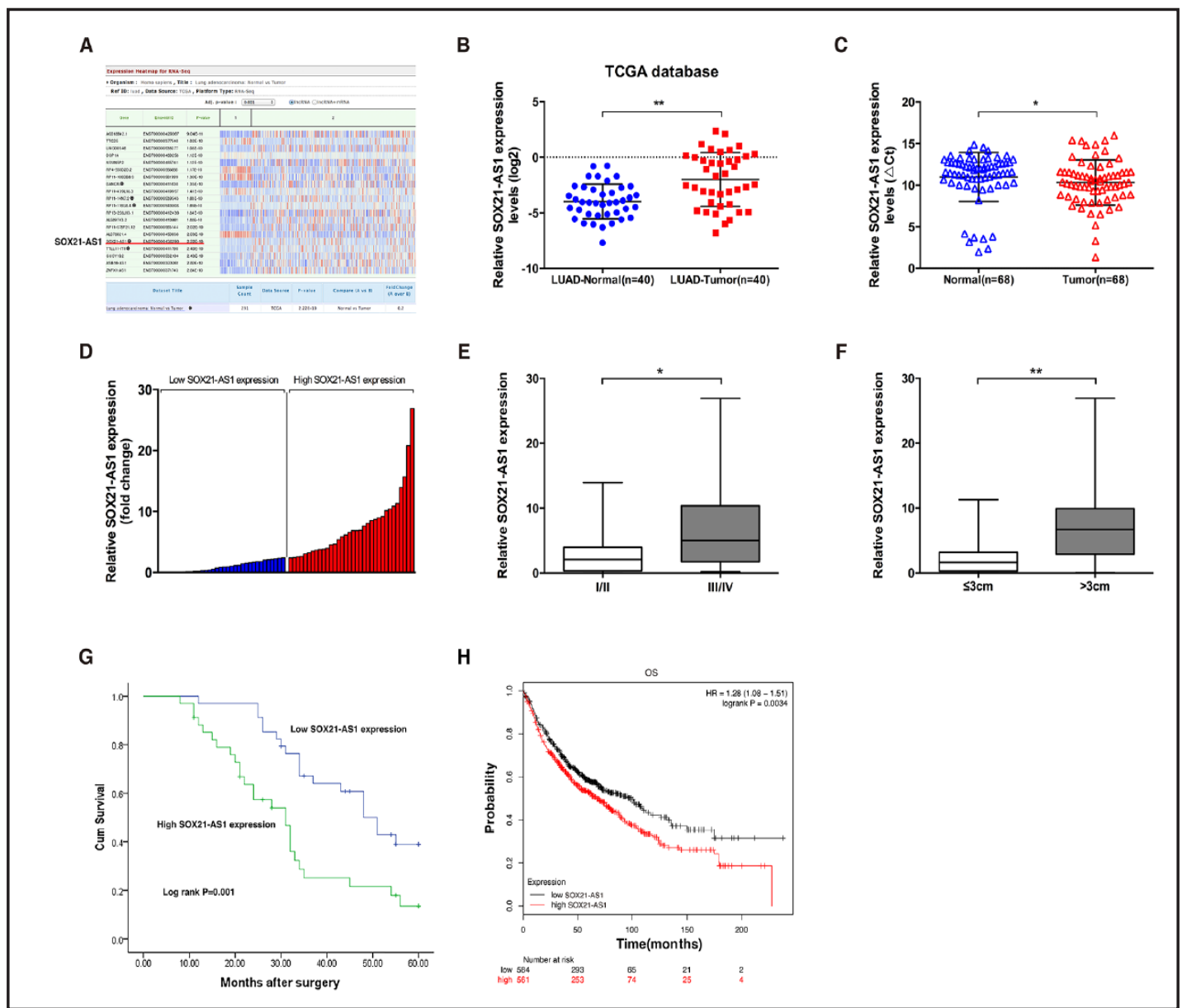

Fig. 1. Relative SOX21-AS1 expression in LUAD tissues and its clinical significance. A. RNA-Seq data from TCGA for IncRNAs in lung adenocarcinoma were analyzed using the bioinformatics tool lncRNAtor (http:// lncrnator.ewha.ac.kr/index.htm). Lung adenocarcinoma: Normal $(\mathrm{n}=46)$ and Tumor $(\mathrm{n}=245)$. B. SOX21AS1 expression in LUAD tissues $(n=40)$ compared with non-cancerous tissues $(n=40)$ analyzed using TCGA database. C. Relative expression levels of SOX21-AS1 in NSCLC tissues ( $n=68)$ compared with corresponding non-tumor tissues $(n=68)$. SOX21-AS1 expression was examined using qPCR and was normalized to GAPDH expression. The $\triangle \mathrm{Ct}$ value was determined by subtracting the GAPDH Ct value from the SOX21-AS1 Ct value (relative to a single reference value). Smaller $\Delta$ Ct values indicate higher expression. D. SOX21-AS1 expression was classified into two groups according to the median SOX21-AS1 expression level value in NSCLC tissue samples. E. SOX21-AS1 expression was significantly higher in patients with higher pathological stages (III/ IV) than in those with lower pathological stages (I/II). F. SOX21-AS1 expression was significantly higher in patients with larger tumor sizes $(>3 \mathrm{~cm})$ than in those with smaller tumor sizes $(\leq 3 \mathrm{~cm})$. G. Kaplan-Meier overall survival (OS) curves according to SOX21-AS1 expression levels. H. Kaplan-Meier survival plots demonstrating that high SOX21-AS1 expression levels correlated with worse OS in lung cancer patients $(\mathrm{n}=$ 1145). *, $\mathrm{P}<0.05$, and $* *, \mathrm{P}<0.01$. 
Lu et al.: SOX21-AS1 Regulates Cell Proliferation of LUAD

normal tissue samples from TCGA. As shown in Fig. 1B, SOX21-AS1 expression levels were significantly upregulated in cancerous tissues $(\mathrm{P}<0.01)$. We also evaluated the expression levels of SOX21-AS1 in 68 pairs of LUAD tissues and adjacent normal tissues by qRT-PCR with normalization to GAPDH. As shown in Fig. 1C, SOX21-AS1 expression levels in tumors were significantly higher $(\mathrm{P}<0.05)$ in $72.1 \%(49 / 68)$ of the samples compared to those of the corresponding normal counterparts, with a 4.29-fold upregulation. The clinical pathological features of the 68 lung adenocarcinoma cases are summarized in Table 1. To further understand the significance of SOX21-AS1 overexpression in LUAD, we used $t$-tests to examine the correlation of SOX21-AS1 expression levels and clinical-pathological factors in patients. The results demonstrated that there was an obvious positive correlation between increased SOX21-AS1 levels and advanced tumor-node-metastasis (TNM) stage $(6.3712 \pm 7.88046$ vs $2.48202 .09170, \mathrm{P}=0.042)$ and larger tumor size $(4.7446 \pm 5.64389$ vs $1.4372 \pm 1.18797, \mathrm{P}<0.001$ ). Patients in stages III/IV or with tumors sizes greater than $3 \mathrm{~cm}$ were associated with higher SOX21-AS1 expression levels, whereas patients in stages I/II or with tumors sizes less than $3 \mathrm{~cm}$ were associated with lower SOX21-AS1 expression levels (Fig. 1E and F). Furthermore, as shown in Fig. 1D, 68 LUAD patients were divided into two groups according to the median value of their SOX21-AS1 expression levels: a high-SOX21AS1 group (above the median, $\mathrm{n}=34$ ) and a low-SOX21-AS1 group (below the median, $\mathrm{n}=$ 34). A Chi-squared test was performed to assess the clinical-pathological factors between the two groups. As shown in Table 2, the SOX21-AS1 expression levels also correlated with TNM stage $(\mathrm{P}=0.033)$ and tumor size $(\mathrm{P}<0.001)$. However, there was no remarkable relationship between SOX21-AS1 expression and other clinical factors such as gender $(\mathrm{P}=0.806)$, age ( $\mathrm{P}$ $=0.627)$, or smoking history $(\mathrm{P}=0.627)$ in our study (Table 2$)$.

To further evaluate the effects of SOX21-AS1 expression on the prognosis of patients with LUAD, we used Kaplan-Meier survival analysis and log-rank tests for overall survival (OS). As shown in Fig. 1G, the overall survival rate over 3 years for the high SOX21-AS1 group was $44.1 \%$, while it was $23.5 \%$ for the low SOX21-AS1 group. The median survival time for the low SOX21-AS1 group was $46.061 \pm 2.491$ months, but it was only $31.736 \pm 2.912$ months for the high SOX21-AS1 group. Remarkably, overexpression of SOX21-AS1 was associated with shorter OS (P = 0.001). Similarly, the correlation between SOX21-AS1 expression levels and the survival of NSCLC patients was also supported by Kaplan-Meier Plotter analysis (www. kmplot.com), which indicated that higher SOX21-AS1 expression correlated with worse OS using publicly available data from 1145 lung cancer patients [30] (Fig. 1H).

Univariate analysis revealed that TNM stage (I/II, III/IV), histological grade (low, middle or high), and SOX21-AS1 expression levels could be viewed as prognostic factors (Table 3). However, there was no statistically significant correlation between SOX21-AS1 and other clinical-pathological characteristics, including sex (male or female) and age ( $\leq 60$ or $>60$ ). Multivariate analysis further showed that SOX21-AS1 expression was a significant independent predictor of poor survival for LUAD patients $(P=0.005)$, as was TNM stage $(\mathrm{P}=0.004)$ and histological grade $(\mathrm{P}=0.010)$. These results indicate that SOX21-AS1 could be a useful marker for the prognosis or progression of LUAD. 
Lu et al.: SOX21-AS1 Regulates Cell Proliferation of LUAD

Table 3. Univariate and multivariate analysis of clinic pathologic factors for overall survival in 68 patients with NSCLC. *HR hazard ratio. $* \mathrm{p}<0.05 . * * \mathrm{p}<0.01$

\begin{tabular}{|c|c|c|c|c|c|c|}
\hline \multirow[t]{2}{*}{ Risk factors } & \multicolumn{3}{|c|}{ Univariate analysis } & \multicolumn{3}{|c|}{ Multivariate analysis } \\
\hline & $\mathrm{HR}^{*}$ & $p$ value & $95 \% \mathrm{CI}$ & $\mathrm{HR}$ & $\mathrm{p}$ value & $95 \% \mathrm{CI}$ \\
\hline SOX21 expression & 1.040 & $0.001^{* *}$ & $1.015 \sim 1.065$ & 1.080 & $0.005^{* *}$ & $1.023 \sim 1.140$ \\
\hline TNM stage ( I / II , III/IV) & 50.180 & $0.001^{* *}$ & $4.509 \sim 558.462$ & 2.838 & $0.004^{* *}$ & $1.399 \sim 5.760$ \\
\hline Histological grade (low, middle or high) & 0.459 & $0.012^{*}$ & $0.250 \sim 0.844$ & 0.429 & $0.010^{*}$ & $0.226 \sim 0.816$ \\
\hline Tumor size $(\leq 3 \mathrm{~cm},>3 \mathrm{~cm})$ & 1.778 & 0.081 & $0.931 \sim 3.396$ & & & \\
\hline $\begin{array}{l}\text { Histological classification (SCC, AD or } \\
\text { another) }\end{array}$ & 1.444 & 0.219 & $0.803 \sim 2.595$ & & & \\
\hline Age $(\leq 60,>60)$ & 0.755 & 0.347 & $0.420 \sim 1.357$ & & & \\
\hline $\mathrm{N}$ (negative, positive) & 1.493 & 0.189 & $0.821 \sim 2.715$ & & & \\
\hline History of smoking (ever, never) & 0.954 & 0.876 & $0.529 \sim 1.721$ & & & \\
\hline Sex (male, female) & 1.266 & 0.431 & $0.704 \sim 2.276$ & & & \\
\hline
\end{tabular}

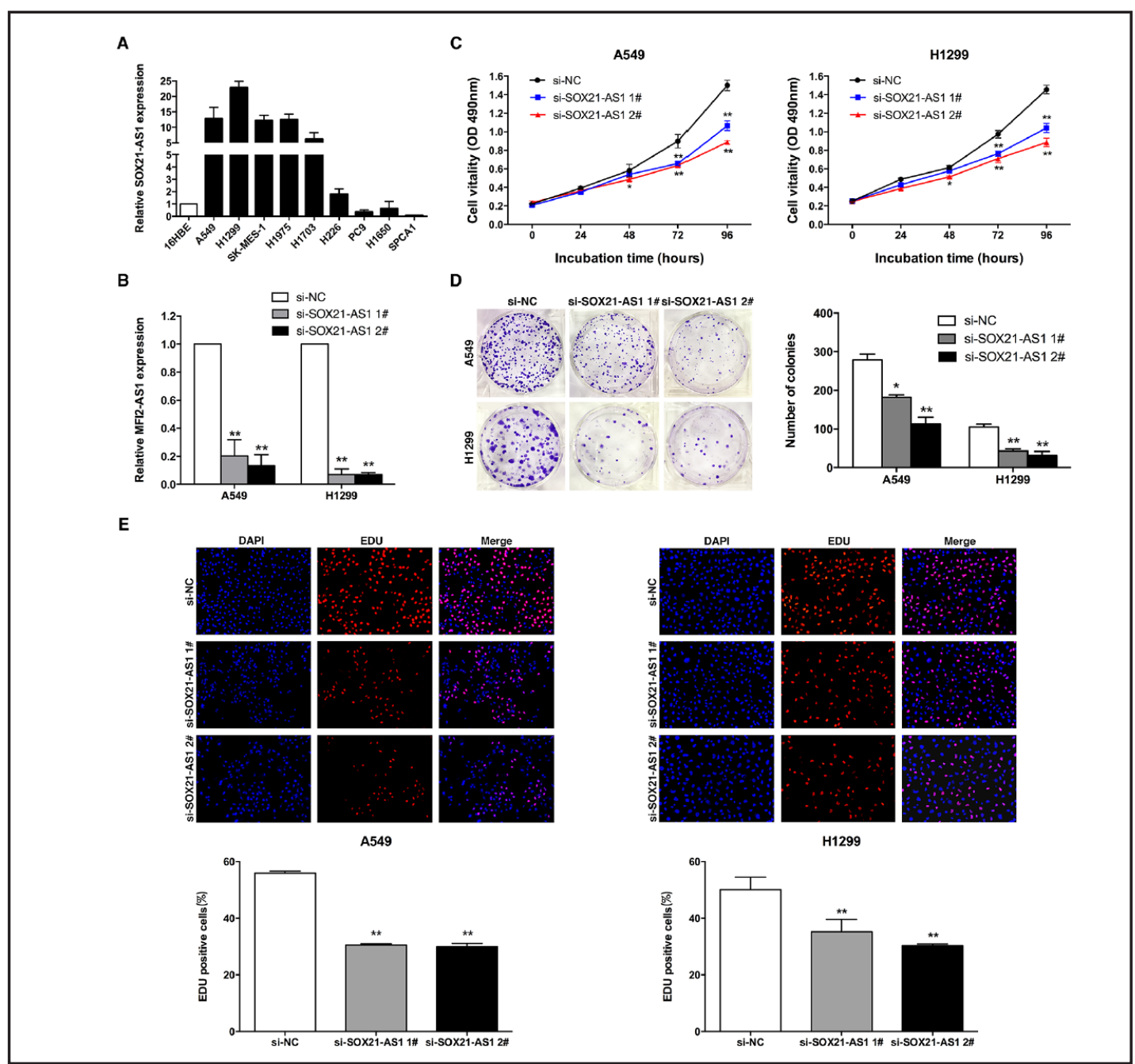

Fig. 2. SOX21-AS1 promotes LUAD cell proliferation in vitro. A. Analysis of SOX21-AS1 expression levels in 9 NSCLC cell lines compared with a normal bronchial epithelial cell line (16HBE) using qRT-PCR. B. The relative expression levels of SOX21-AS1 in A549 and H1299 cells transfected with si-NC or si-SOX21-AS1 (si-SOX21-AS1 1\# and si-SOX21-AS1 2\#) were measured using qPCR. C. MTT assays were performed $24 \mathrm{~h}$ after transfection to determine the cell viability of the transfected A549 and H1299 cells. D. Colony-forming assays were conducted $24 \mathrm{~h}$ after transfection to determine the proliferation of the transfected A549 and H1299 cells. The colonies were counted and captured. E. EdU (red)/DAPI (blue) assays were conducted 24 $\mathrm{h}$ after transfection to determine the viability of the transfected A549 and H1299 cells. The data represent the mean \pm SD from three independent experiments. *, $\mathrm{P}<0.05$, and ${ }^{* *}, \mathrm{P}<0.01$. 


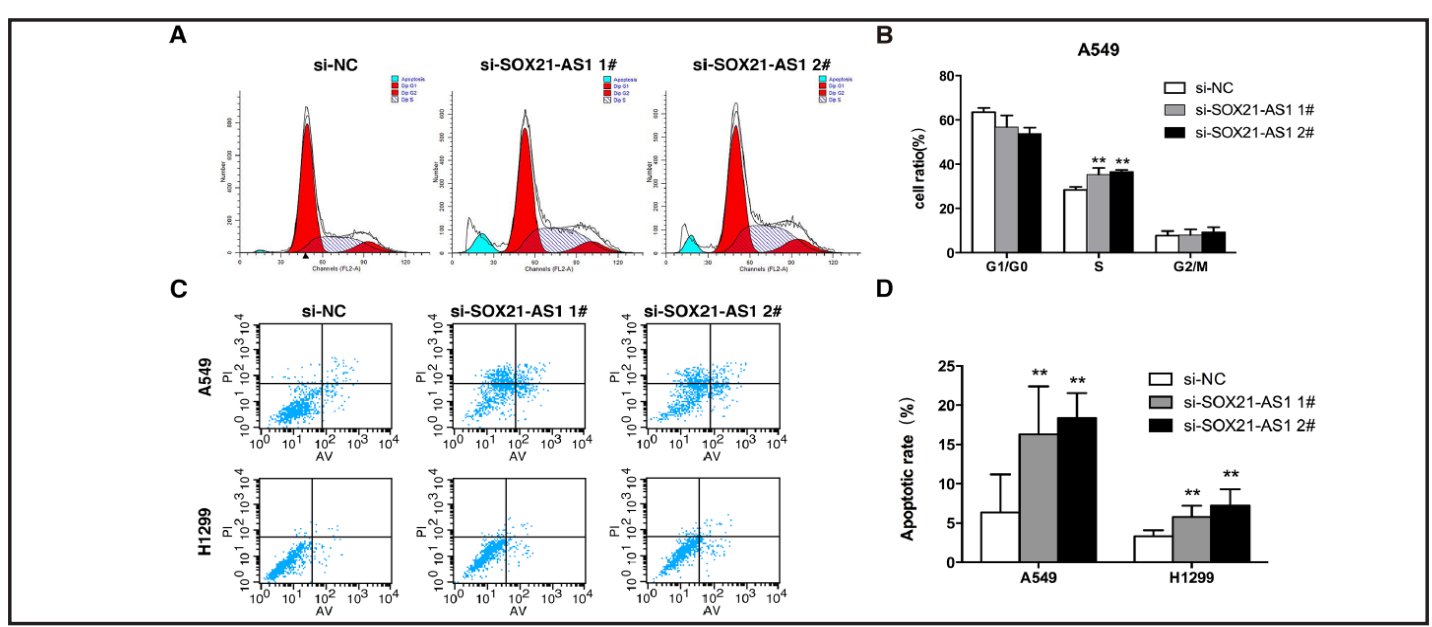

Fig. 3. The effects of SOX21-AS1 on LUAD cell cycle and apoptosis in vitro. A, B. Forty-eight hours after transfection, the cell cycle stages of A549 cells were analyzed by flow cytometry. The bar chart represents the percentages of cells in the G1/G0, S, or G2/M phases, as indicated. C, D. A549 and H1299 cells were stained and analyzed by flow cytometry $48 \mathrm{~h}$ after transfection. LR, early apoptotic cells; UR, terminal apoptotic cells. All experiments were conducted in biological triplicates with three technical replicates. Data are presented as the mean \pm SD. $*, P<0.05$, and $* *, P<0.01$.

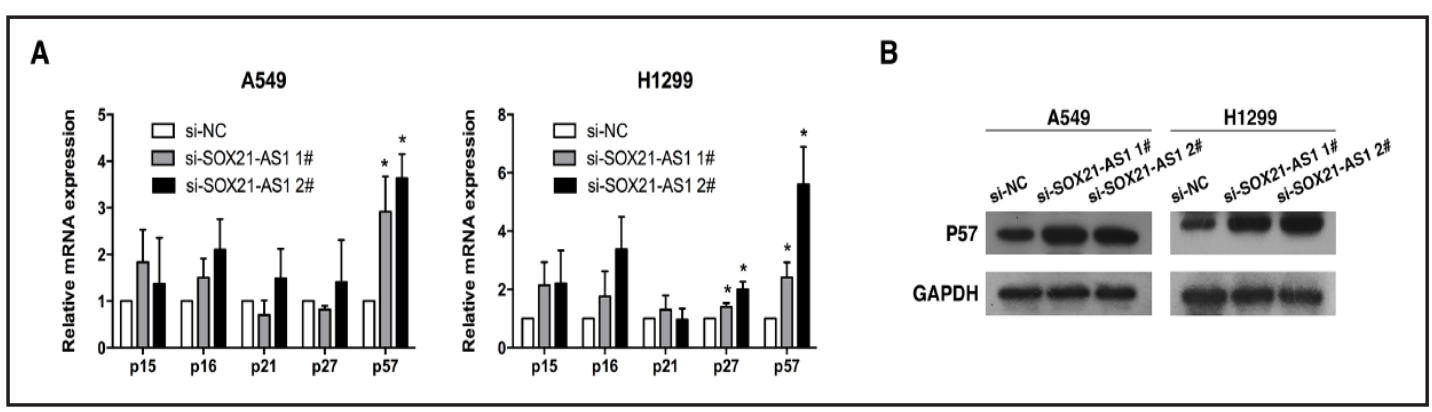

Fig. 4. SOX21-AS1 could regulate the expression of p57. A. The expression levels of cell cycle-related genes were determined after knockdown of SOX21-AS1 using qRT-PCR. Significant upregulation of p57 was observed in A549 and H1299 cells. B. Western blot assays confirmed the expression of p57 after transfection. GAPDH protein was used as an internal control. The results shown are from three independent experiments. $*, \mathrm{P}<0.05$, and $* *, \mathrm{P}<0.01$.

Knockdown of SOX21-AS1 inhibits cell proliferation in vitro

To gain insight into the biological functional of SOX21-AS1 in LUAD cells, we first detected the expression of SOX21-AS1 in a normal human bronchial epithelial cell line (16HBE) and diverse human NSCLC cell lines using qRT-PCR analysis. As shown in Fig. 2A, SOX21-AS1 expression was significantly upregulated in two LUAD cell lines (A549 and H1299) compared with 16HBE. Thus, the A549 and H1299 cell lines were chosen for further study. Next, we synthesized two different siRNAs to silence endogenous SOX21-AS1 in A549 and H1299 cells. Forty-eight hours after transfection, SOX21-AS1 expression was knocked down by $79.6 \%$ in A549 cells and by $86.7 \%$ in $\mathrm{H} 1299$ cells relative to the control siRNAtransfected cells (Fig. 2B). Subsequent MTT assays demonstrated that knockdown of SOX21AS1 expression significantly attenuated the cell viability rate in A549 and H1299 cells (Fig. 2C). In addition, colony-formation assays revealed that colony-forming ability was greatly reduced following downregulation of SOX21-AS1 in A549 and H1299 cells (Fig. 2D). Similarly, microscopic analysis of 5-ethynyl-2-deoxyuridine (EdU) (red)/DAPI (blue) immunostaining assays confirmed these findings (Fig. 2E). Collectively, these data indicate that SOX21-AS1 exerts an oncogenic effect to promote the proliferation of lung adenocarcinoma cells.

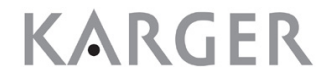




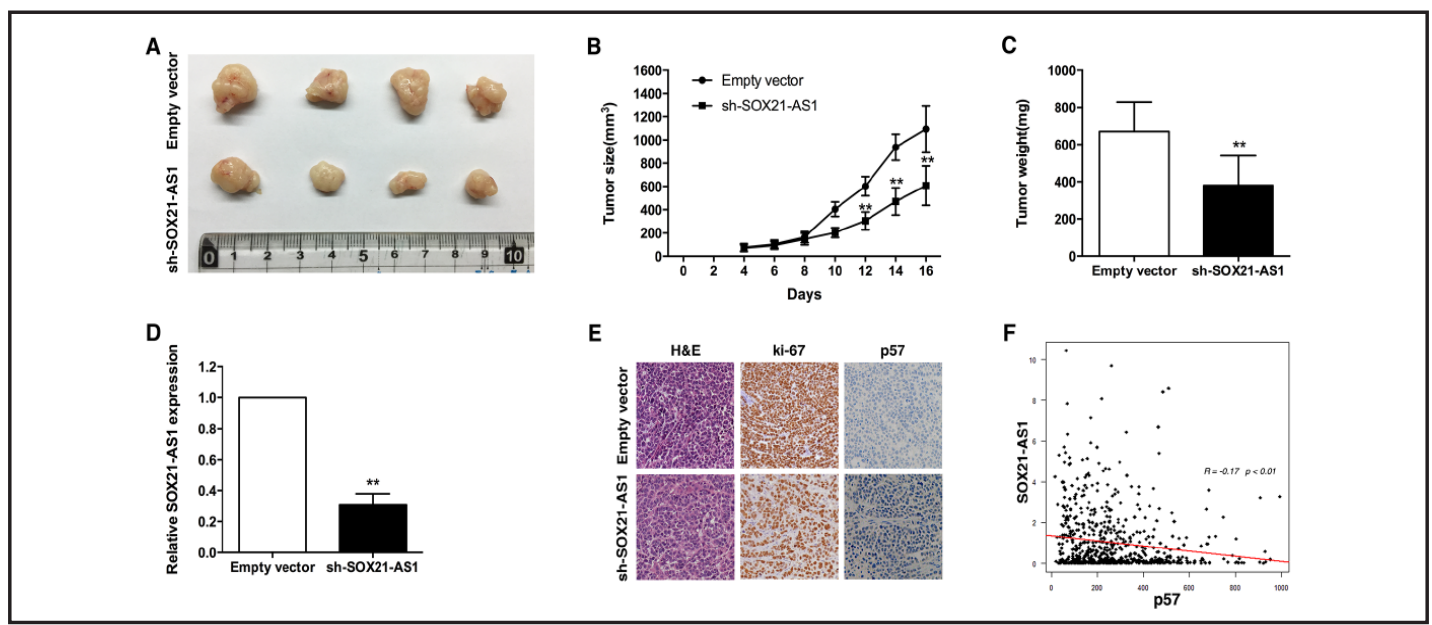

Fig. 5. SOX21-AS1 promotes the tumorigenesis of LUAD cells in vivo. A. Empty vector or sh-SOX21-AS1 was transfected into A549 cells, which were then injected individual into nude mice $(\mathrm{n}=4)$. B. The tumor volumes were calculated every two days after injection. The mean tumor volumes are indicated by points, and the bars indicate SD $(n=4)$. C. The tumor weights are represented as the mean tumor weights \pm SD. D. qRT-PCR analysis was performed to detect the average expression levels of SOX21-AS1 in the xenograft tumors $(n=4)$. E. The tumor sections were examined using H\&E staining and IHC staining with antibodies against Ki-67 and p57. The error bars indicate the mean \pm standard error. F. Correlation analysis revealed that SOX21-AS1 expression levels were inversely correlated with p57 expression levels in lung cancer from TCGA data. *, $\mathrm{P}<0.05$, and ${ }^{* *}, \mathrm{P}<0.01$.

To further explore whether SOX21-AS1 impacts the proliferation of LUAD cells through cell cycle regulation, we tested cell cycle progression using flow cytometric analysis. The results showed that A549 cells transfected with si-SOX21-AS1 had cell-cycle arrest at the S phase compared with cells transfected with si-NC (Fig. 3A and B). Additionally, we performed flow cytometric analysis to determine whether cell proliferation was influenced by cell apoptosis. The results indicated that knockdown of SOX21-AS1 significantly induced LUAD cell apoptosis (Fig. 3C and D).

\section{Knockdown of SOX21-AS1 induces p57 expression}

To investigate the role of SOX21-AS1 in S arrest, we examined the effect of SOX21-AS1 silencing on the expression of cyclin-dependent protein kinase inhibitors via qRT-PCR. Strikingly, we discovered that the inhibition of SOX21-AS1 led to increased levels of p57 in both A549 and H1299 cells (Fig. 4A). To further determine whether the protein levels of p57 were increased with the knockdown of SOX21-AS1, we performed a Western blot assay. The repression of SOX21-AS1 increased the protein levels of p57 in both A549 and H1299 cells compared with control cells (Fig. 4B). Taken together, these results indicated that SOX21AS1 promotes LUAD cell proliferation partially by silencing p57 expression.

\section{Knockdown of SOX21-AS1 inhibits LUAD cell tumorigenesis in vivo}

To confirm the effect of SOX21-AS1 expression on tumorigenesis in vivo, we used a xenograft mouse model. A549 cells stably transfected with sh-SOX21-AS1 or an empty vector were subcutaneously injected into male nude mice. We observed that all mice developed xenograft tumors at the injection site. As shown in Fig. 5A and B, SOX21-AS1 silencing substantially suppressed tumor growth compared to the control group. In addition, up to the 16th day after injection, the average tumor weight in the sh-SOX21-AS1 group was obviously lower than that in the control group (Fig. 5C). Subsequently, qRT-PCR analysis also revealed that the average expression level of SOX21-AS1 in tumors formed from sh-SOX21- 
AS1 cells was lower than in tumors formed in the control group (Fig. 5D). Moreover, using immunohistochemical staining, the tumors developed from sh-SOX21-AS1 cells displayed lower Ki-67 staining and higher p57 staining than the tumors formed from empty vector transfected cells (Fig. 5E). Furthermore, correlation analysis revealed that SOX21-AS1 expression levels negatively correlated with p57 expression levels in lung cancer samples from TCGA data. These results further indicate the important role of SOX21-AS1 in lung adenocarcinoma cell proliferation.

\section{Discussion}

Over the past few decades, the roles of lncRNAs in human disease, including cancer, have attracted much attention [31-33]. Mounting studies have revealed that lncRNAs have crucial roles in various cancer types by functioning as potential oncogenes or tumor suppressors [18, 34-37]. For instance, IncRNA HOTAIR, a famous lncRNA, is a strong prognostic marker for diverse human cancers [38-40]. In our previous studies, we found that SP1-induced overexpression of the IncRNA TINCR promotes cell proliferation by influencing KLF2 mRNA stability in gastric cancer [41]. We also explored whether the E2F1-mediated upregulation of Linc00668 predicts poor prognosis in gastric cancer and if it regulates cell proliferation via the silencing of CKIs [42]. However, only a handful of lncRNAs are known to be involved in NSCLC tumorigenesis as the study of NSCLC IncRNAs is an emerging field.

In the present study, we identified a novel IncRNA, SOX21-AS1, using bioinformatics methods. First, we analyzed the expression profiles of SOX21-AS1 in LUAD samples in the TCGA database and validated the results in a cohort of 68 pairs of LUAD tumorous and normal tissue samples. The results showed that SOX21-AS1 was upregulated in LUAD tissues and obviously correlated with poor prognosis and shorter survival. Specifically, patients with higher SOX21-AS1 expression levels seemed to harbor larger tumor sizes and were characterized by higher TNM stages. We further determined that SOX21-AS1 expression was an independent predictor for overall survival. Moreover, silencing SOX21-AS1 impaired cell proliferation and facilitated cell apoptosis in vitro and inhibited tumorigenesis of LUAD cells in vivo, implying that SOX21-AS1 could be a biomarker and therapeutic target for LUAD.

p57Kip2 is deemed to be a candidate tumor suppressor gene that blocks cell proliferation by inhibiting cell cycle progression and by promoting apoptosis and cell differentiation [43, 44]. The functional roles of p57 have been illustrated in carcinomas of the stomach, liver, prostate, breast, bladder, and other organs [45-49]. Therefore, the expression of p57 is frequently repressed in a wide variety of cancers to facilitate cell proliferation [50-52]. In this study, we examined the effect of SOX21-AS1 inhibition on the expression of several CKI family proteins involved in the S checkpoint of the cell cycle in A549 and H1299 cells. After inhibition of SOX21-AS1, we observed a significant increase in the expression of p57 (Fig. $4 \mathrm{~A}, \mathrm{~B}$ ). These data further verified that knockdown of SOX21-AS1 can induce p57 expression and SOX21-AS1 could play an important role in the cell cycle of LUAD. A large number of long non-coding RNAs have recently been reported to have a direct role in recruiting RNA-binding proteins to specific loci and in repressing gene expression in multiple cancers including NSCLC $[23,27,53]$. Thus, we hypothesize that SOX21-AS1 may repress p57 transcription via binding to related proteins, but further work is needed for confirmation.

Collectively, in this study, we clarified that SOX21-AS1 was upregulated in LUAD tumorous tissues and cell lines and correlated with poor prognosis in LUAD patients. Our findings imply that SOX21-AS1 could be a potential diagnostic and prognostic marker in patients with LUAD. In future studies, we will increase the number of samples for further investigation and attempt to elucidate the concise molecular mechanisms underlying the altered expression of SOX21-AS1 in LUAD. 


\section{Cellular Physiology Cell Physiol Biochem 2017;42:1857-1869 \\ \begin{tabular}{l|l} 
and Biochemistry Published online: July 28, 2017 & $\begin{array}{l}\text { C) } 2017 \text { The Author(s). Published by S. Karger AG, Basel } \\
\text { www.karger.com/cpb }\end{array}$ \\
\hline
\end{tabular}}

Lu et al.: SOX21-AS1 Regulates Cell Proliferation of LUAD

\section{Acknowledgements}

This work was supported by grants from the National Natural Science Foundation of China (81172217), the Natural Science Foundation of Jiangsu Province (BK20161593), China Postdoctoral Science Foundation(2017M610339), the Medical Important Talents of Jiangsu Province (RC201157) and the Wu Jie-ping Foundation (320.6799.15032).

\section{Disclosure Statement}

The authors declare no conflicts of interest.

\section{References}

1 Siegel RL, Miller KD, Jemal A: Cancer statistics, 2016. CA Cancer J Clin 2016;66:7-30.

-2 DeSantis CE, Lin CC, Mariotto AB, Siegel RL, Stein KD, Kramer JL, Alteri R, Robbins AS, Jemal A: Cancer treatment and survivorship statistics, 2014. CA Cancer J Clin 2014;64:252-271.

3 Chen W, Zheng R, Baade PD, Zhang S, Zeng H, Bray F, Jemal A, Yu XQ He J: Cancer statistics in China, 2015. CA Cancer J Clin 2016;66:115-132.

- Herbst RS, Heymach JV, Lippman SM: Lung cancer. N Engl J Med 2008;359:1367-1380.

-5 Verdecchia A, Francisci S, Brenner H, Gatta G, Micheli A, Mangone L, Kunkler I, Group E-W: Recent cancer survival in Europe: a 2000-02 period analysis of EUROCARE-4 data. Lancet Oncol 2007;8:784-796.

6 Guttman M, Amit I, Garber M, French C, Lin MF, Feldser D, Huarte M, Zuk O, Carey BW, Cassady JP, Cabili MN, Jaenisch R, Mikkelsen TS, Jacks T, Hacohen N, Bernstein BE, Kellis M, Regev A, Rinn JL, Lander ES: Chromatin signature reveals over a thousand highly conserved large non-coding RNAs in mammals. Nature 2009;458:223-227.

7 Djebali S, Davis CA, Merkel A, Dobin A, Lassmann T, Mortazavi A, Tanzer A, Lagarde J, Lin W, Schlesinger F, Xue C, Marinov GK, Khatun J, Williams BA, Zaleski C, Rozowsky J, Roder M, Kokocinski F, Abdelhamid RF, Alioto T, Antoshechkin I, Baer MT, Bar NS, Batut P, Bell K, Bell I, Chakrabortty S, Chen X, Chrast J, Curado J, Derrien T, Drenkow J, Dumais E, Dumais J, Duttagupta R, Falconnet E, Fastuca M, Fejes-Toth K, Ferreira P, Foissac S, Fullwood MJ, Gao H, Gonzalez D, Gordon A, Gunawardena H, Howald C, Jha S, Johnson R, Kapranov P, King B, Kingswood C, Luo OJ, Park E, Persaud K, Preall JB, Ribeca P, Risk B, Robyr D, Sammeth M, Schaffer L, See LH, Shahab A, Skancke J, Suzuki AM, Takahashi H, Tilgner H, Trout D, Walters N, Wang H, Wrobel J, Yu Y, Ruan X, Hayashizaki Y, Harrow J, Gerstein M, Hubbard T, Reymond A, Antonarakis SE, Hannon G, Giddings MC, Ruan Y, Wold B, Carninci P, Guigo R, Gingeras TR: Landscape of transcription in human cells. Nature 2012;489:101-108.

8 Elgar G, Vavouri T: Tuning in to the signals: noncoding sequence conservation in vertebrate genomes. Trends Genet 2008;24:344-352.

-9 Mercer TR, Dinger ME, Mattick JS: Long non-coding RNAs: insights into functions. Nat Rev Genet 2009;10:155-159.

10 Orom UA, Derrien T, Beringer M, Gumireddy K, Gardini A, Bussotti G, Lai F, Zytnicki M, Notredame C, Huang Q Guigo R, Shiekhattar R: Long noncoding RNAs with enhancer-like function in human cells. Cell 2010;143:46-58.

11 Ginger MR, Shore AN, Contreras A, Rijnkels M, Miller J, Gonzalez-Rimbau MF, Rosen JM: A noncoding RNA is a potential marker of cell fate during mammary gland development. Proc Natl Acad Sci U S A 2006;103:5781-5786.

12 Wang P, Xue Y, Han Y, Lin L, Wu C, Xu S, Jiang Z, Xu J, Liu Q, Cao X: The STAT3-binding long noncoding RNA lnc-DC controls human dendritic cell differentiation. Science 2014;344:310-313.

13 Cesana M, Cacchiarelli D, Legnini I, Santini T, Sthandier O, Chinappi M, Tramontano A, Bozzoni I: A long noncoding RNA controls muscle differentiation by functioning as a competing endogenous RNA. Cell 2011;147:358-369.

14 Chen Y, Li C, Pan Y, Han S, Feng B, Gao Y, Chen J, Zhang K, Wang R, Chen L: The Emerging Role and Promise of Long Noncoding RNAs in Lung Cancer Treatment. Cell Physiol Biochem 2016;38:2194-2206. 


\section{Cellular Physiology Cell Physiol Biochem 2017;42:1857-1869 \begin{tabular}{l|l|l}
\hline DOI: 10.1159/000479543 & $\begin{array}{l}\text { C } 2017 \text { The Author(s). Published by S. Karger AG, Basel } \\
\text { www.karger.com/cpb }\end{array}$ \\
\hline
\end{tabular}}

Lu et al.: SOX21-AS1 Regulates Cell Proliferation of LUAD

15 Qiu ZL, Shen CT, Sun ZK, Wei WJ, Zhang XY, Song HJ, Luo QY: Circulating Long Non-Coding RNAs Act as Biomarkers for Predicting 131I Uptake and Mortality in Papillary Thyroid Cancer Patients with Lung Metastases. Cell Physiol Biochem 2016;40:1377-1390.

-16 Leucci E, Vendramin R, Spinazzi M, Laurette P, Fiers M, Wouters J, Radaelli E, Eyckerman S, Leonelli C, Vanderheyden K, Rogiers A, Hermans E, Baatsen P, Aerts S, Amant F, Van Aelst S, van den Oord J, de Strooper B, Davidson I, Lafontaine DL, Gevaert K, Vandesompele J, Mestdagh P, Marine JC: Melanoma addiction to the long non-coding RNA SAMMSON. Nature 2016;531:518-522.

17 Sun M, Kraus WL: From discovery to function: the expanding roles of long noncoding RNAs in physiology and disease. Endocr Rev 2015;36:25-64.

18 Gupta RA, Shah N, Wang KC, Kim J, Horlings HM, Wong DJ, Tsai MC, Hung T, Argani P, Rinn JL, Wang Y, Brzoska P, Kong B, Li R, West RB, van de Vijver MJ, Sukumar S, Chang HY: Long non-coding RNA HOTAIR reprograms chromatin state to promote cancer metastasis. Nature 2010;464:1071-1076.

19 Khaitan D, Dinger ME, Mazar J, Crawford J, Smith MA, Mattick JS, Perera RJ: The melanoma-upregulated long noncoding RNA SPRY4-IT1 modulates apoptosis and invasion. Cancer Res 2011;71:3852-3862.

20 Pandey GK, Mitra S, Subhash S, Hertwig F, Kanduri M, Mishra K, Fransson S, Ganeshram A, Mondal T, Bandaru S, Ostensson M, Akyurek LM, Abrahamsson J, Pfeifer S, Larsson E, Shi L, Peng Z, Fischer M, Martinsson T, Hedborg F, Kogner P, Kanduri C: The risk-associated long noncoding RNA NBAT-1 controls neuroblastoma progression by regulating cell proliferation and neuronal differentiation. Cancer cell 2014;26:722-737.

21 Garzon R, Volinia S, Papaioannou D, Nicolet D, Kohlschmidt J, Yan PS, Mrozek K, Bucci D, Carroll AJ, Baer MR, Wetzler M, Carter TH, Powell BL, Kolitz JE, Moore JO, Eisfeld AK, Blachly JS, Blum W, Caligiuri MA, Stone RM, Marcucci G, Croce CM, Byrd JC, Bloomfield CD: Expression and prognostic impact of IncRNAs in acute myeloid leukemia. Proc Natl Acad Sci U S A 2014;111:18679-18684.

-22 Prensner JR, Iyer MK, Balbin OA, Dhanasekaran SM, Cao Q, Brenner JC, Laxman B, Asangani IA, Grasso CS, Kominsky HD, Cao X, Jing X, Wang X, Siddiqui J, Wei JT, Robinson D, Iyer HK, Palanisamy N, Maher CA, Chinnaiyan AM: Transcriptome sequencing across a prostate cancer cohort identifies PCAT-1, an unannotated lincRNA implicated in disease progression. Nat Biotechnol 2011;29:742-749.

-23 Zhang E, Han L, Yin D, He X, Hong L, Si X, Qiu M, Xu T, De W, Xu L, Shu Y, Chen J: H3K27 acetylation activated-long non-coding RNA CCAT1 affects cell proliferation and migration by regulating SPRY4 and HOXB13 expression in esophageal squamous cell carcinoma. Nucleic Acids Res 2017;45:3086-3101.

24 Tang Q, Ni Z, Cheng Z, Xu J, Yu H, Yin P: Three circulating long non-coding RNAs act as biomarkers for predicting NSCLC. Cell Physiol Biochem 2015;37:1002-1009.

25 Gutschner T, Hammerle M, Eissmann M, Hsu J, Kim Y, Hung G, Revenko A, Arun G, Stentrup M, Gross M, Zornig M, MacLeod AR, Spector DL, Diederichs S: The noncoding RNA MALAT1 is a critical regulator of the metastasis phenotype of lung cancer cells. Cancer Res 2013;73:1180-1189.

26 Chen Z, Li JL, Lin S, Cao C, Gimbrone NT, Yang R, Fu DA, Carper MB, Haura EB, Schabath MB, Lu J, Amelio AL, Cress WD, Kaye FJ, Wu L: cAMP/CREB-regulated LINC00473 marks LKB1-inactivated lung cancer and mediates tumor growth. J Clin Invest 2016;126:2267-2279.

-27 Li W, Sun M, Zang C, Ma P, He J, Zhang M, Huang Z, Ding Y, Shu Y: Upregulated long non-coding RNA AGAP2AS1 represses LATS2 and KLF2 expression through interacting with EZH2 and LSD1 in non-small-cell lung cancer cells. Cell Death Dis 2016;7:e2225.

28 Zhang EB, Yin DD, Sun M, Kong R, Liu XH, You LH, Han L, Xia R, Wang KM, Yang JS, De W, Shu YQ Wang ZX: P53-regulated long non-coding RNA TUG1 affects cell proliferation in human non-small cell lung cancer, partly through epigenetically regulating HOXB7 expression. Cell Death Dis 2014;5:e1243.

29 Qiu M, Xu Y, Wang J, Zhang E, Sun M, Zheng Y, Li M, Xia W, Feng D, Yin R, Xu L: A novel lncRNA, LUADT1, promotes lung adenocarcinoma proliferation via the epigenetic suppression of p27. Cell Death Dis 2015;6:e1858.

-30 Gyorffy B, Surowiak P, Budczies J, Lanczky A: Online survival analysis software to assess the prognostic value of biomarkers using transcriptomic data in non-small-cell lung cancer. PLoS One 2013;8:e82241.

-31 Tsai MC, Spitale RC, Chang HY: Long intergenic noncoding RNAs: new links in cancer progression. Cancer Res 2011;71:3-7.

-32 Gibb EA, Brown CJ, Lam WL: The functional role of long non-coding RNA in human carcinomas. Mol Cancer 2011;10:38. 


\section{Cellular Physiology Cell Physiol Biochem 2017;42:1857-1869 \begin{tabular}{l|l|} 
and Biochemistry Published online: July 28, 2017 & $\begin{array}{l}\text { C } 2017 \text { The Author(s). Published by S. Karger AG, Basel } \\
\text { www.karger.com/cpb }\end{array}$ \\
\hline
\end{tabular}}

Lu et al.: SOX21-AS1 Regulates Cell Proliferation of LUAD

-33 Zhu Q, Lv T, Wu Y, Shi X, Liu H, Song Y: Long non-coding RNA 00312 regulated by HOXA5 inhibits tumour proliferation and promotes apoptosis in Non-small cell lung cancer. J Cell Mol Med 2017

-34 Arab K, Park YJ, Lindroth AM, Schafer A, Oakes C, Weichenhan D, Lukanova A, Lundin E, Risch A, Meister M, Dienemann H, Dyckhoff G, Herold-Mende C, Grummt I, Niehrs C, Plass C: Long noncoding RNA TARID directs demethylation and activation of the tumor suppressor TCF21 via GADD45A. Molecular cell 2014;55:604-614.

-35 Sun M, Gadad SS, Kim DS, Kraus WL: Discovery, Annotation, and Functional Analysis of Long Noncoding RNAs Controlling Cell-Cycle Gene Expression and Proliferation in Breast Cancer Cells. Mol Cell 2015;59:698-711.

-36 Yang ZT, Li Z, Wang XG, Tan T, Yi F, Zhu H, Zhao JP, Zhou XF: Overexpression of Long Non-Coding RNA ZXF2 Promotes Lung Adenocarcinoma Progression Through c-Myc Pathway. Cell Physiol Biochem 2015;35:23602370.

37 Wang L, Chen Z, An L, Wang Y, Zhang Z, Guo Y, Liu C: Analysis of Long Non-Coding RNA Expression Profiles in Non-Small Cell Lung Cancer. Cell Physiol Biochem 2016;38:2389-2400.

38 Kogo R, Shimamura T, Mimori K, Kawahara K, Imoto S, Sudo T, Tanaka F, Shibata K, Suzuki A, Komune S, Miyano S, Mori M: Long noncoding RNA HOTAIR regulates polycomb-dependent chromatin modification and is associated with poor prognosis in colorectal cancers. Cancer Res 2011;71:6320-6326.

39 Geng YJ, Xie SL, Li Q, Ma J, Wang GY: Large intervening non-coding RNA HOTAIR is associated with hepatocellular carcinoma progression. J Int Med Res 2011;39:2119-2128.

-40 Niinuma T, Suzuki H, Nojima M, Nosho K, Yamamoto H, Takamaru H, Yamamoto E, Maruyama R, Nobuoka T, Miyazaki Y, Nishida T, Bamba T, Kanda T, Ajioka Y, Taguchi T, Okahara S, Takahashi H, Nishida Y, Hosokawa M, Hasegawa T, Tokino T, Hirata K, Imai K, Toyota M, Shinomura Y: Upregulation of miR-196a and HOTAIR drive malignant character in gastrointestinal stromal tumors. Cancer Res 2012;72:1126-1136.

41 Xu TP, Liu XX, Xia R, Yin L, Kong R, Chen WM, Huang MD, Shu YQ: SP1-induced upregulation of the long noncoding RNA TINCR regulates cell proliferation and apoptosis by affecting KLF2 mRNA stability in gastric cancer. Oncogene 2015;34:5648-5661.

42 Zhang E, Yin D, Han L, He X, Si X, Chen W, Xia R, Xu T, Gu D, De W, Guo R, Xu Z, Chen J: E2F1-induced upregulation of long noncoding RNA LINC00668 predicts a poor prognosis of gastric cancer and promotes cell proliferation through epigenetically silencing of CKIs. Oncotarget 2016;7:23212-23226.

43 Kavanagh E, Joseph B: The hallmarks of CDKN1C (p57, KIP2) in cancer. Biochim Biophys Acta 2011;1816:50-56.

44 Matsuoka S, Edwards MC, Bai C, Parker S, Zhang P, Baldini A, Harper JW, Elledge SJ: p57KIP2, a structurally distinct member of the p21CIP1 Cdk inhibitor family, is a candidate tumor suppressor gene. Genes Dev 1995;9:650-662.

45 Shin JY, Kim HS, Park J, Park JB, Lee JY: Mechanism for inactivation of the KIP family cyclin-dependent kinase inhibitor genes in gastric cancer cells. Cancer Res 2000;60:262-265.

-46 Shin JY, Kim HS, Lee KS, Kim J, Park JB, Won MH, Chae SW, Choi YH, Choi KC, Park YE, Lee JY: Mutation and expression of the p27KIP1 and p57KIP2 genes in human gastric cancer. Exp Mol Med 2000;32:79-83.

47 Fornari F, Gramantieri L, Ferracin M, Veronese A, Sabbioni S, Calin GA, Grazi GL, Giovannini C, Croce CM, Bolondi L, Negrini M: MiR-221 controls CDKN1C/p57 and CDKN1B/p27 expression in human hepatocellular carcinoma. Oncogene 2008;27:5651-5661.

48 Jin RJ, Lho Y, Wang Y, Ao M, Revelo MP, Hayward SW, Wills ML, Logan SK, Zhang P, Matusik RJ: Downregulation of p57Kip2 induces prostate cancer in the mouse. Cancer Res 2008;68:3601-3608.

49 Hoffmann MJ, Florl AR, Seifert HH, Schulz WA: Multiple mechanisms downregulate CDKN1C in human bladder cancer. Int J Cancer 2005; 114:406-413.

50 Oya M, Schulz WA: Decreased expression of p57(KIP2)mRNA in human bladder cancer. Br J Cancer 2000;83:626-631.

51 Mishra S, Lin CL, Huang TH, Bouamar H, Sun LZ: MicroRNA-21 inhibits p57Kip2 expression in prostate cancer. Mol Cancer 2014;13:212.

-52 Yang X, Karuturi RK, Sun F, Aau M, Yu K, Shao R, Miller LD, Tan PB, Yu Q: CDKN1C (p57) is a direct target of EZH2 and suppressed by multiple epigenetic mechanisms in breast cancer cells. PLoS One 2009;4:e5011.

53 Xie M, Sun M, Zhu YN, Xia R, Liu YW, Ding J, Ma HW, He XZ, Zhang ZH, Liu ZJ, Liu XH, De W: Long noncoding RNA HOXA-AS2 promotes gastric cancer proliferation by epigenetically silencing P21/PLK3/DDIT3 expression. Oncotarget 2015;6:33587-33601. 